\title{
Experiencia del poema y asidero plástico, de Luis Cernuda a Rosalía Castro
}

\author{
LUIS CAPARRÓS ESPERANTE \\ Universidade da Coruña \\ orcid.org/0000-0002-7583-6721 \\ luis.caparros@udc.es
}

\begin{abstract}
La expresión 'asidero plástico' la usa Cernuda para describir la necesidad de anclar el poema en los sentidos, de darle consistencia material para hacerlo creíble o 'verdad'. Más allá de su lectura, el poema es experiencia. En otro lugar, menciona la 'falacia patética', de Ruskin, como forma de enmascaramiento sentimental de esa 'verdad'. Todo apuntaría así a una enunciación poética en donde el sujeto procura objetivar su 'experiencia emotiva' y evita nombrarla directamente. Se trata de construirla en la subjetividad de quien lee. El término experiencia se liga a proceso: 'el proceso de mi experiencia'. Es conocimiento logrado mediante una inmersión activa, anterior y posterior al texto escrito, donde intervienen sentidos y pensamiento, entidades complementarias, nunca hostiles. El poema es así una nueva experiencia del objeto. El artículo recorre esta búsqueda en la poesía anterior de paisaje, fórmula romántica favorita, desde las insuficiencias de Gil Carrasco a los logros de Antonio Machado con el precedente brillante de Rosalía Castro.
\end{abstract}

'Asidero plástico' is the term used by Cernuda to describe the need for anchor the poem in the senses, to give it a material consistency aimed at its credibility or 'truth'. Beyond its reading, the poem is experience. Elsewhere, he mentions Ruskin's 'pathetic fallacy' as a form of sentimental masking of that 'truth'. Everything points to a poetic enunciation with the lyrical voice trying to objectify its 'emotional experience' and avoiding its direct naming. The key is constructing it in the reader's subjectivity. The term 'experience' is linked to 'process': 'the process of my experience'. It is knowledge achieved through active immersion, before and after the written text, where senses and thought are present as complementary entities, never hostile. The poem is thus a new experience of the object. The article goes through this search in previous poetry of landscape, romantic formula favorite, from Gil y Carrasco's insufficiencies to Antonio Machado's achievements and the brilliant precedent of Rosalía Castro.

\section{KEY WORDS}

Luis Cernuda. Gil y Carrasco. Antonio Machado. Rosalía Castro. Falacia poética. Poéticas de la Modernidad. Sensaciones. Poesía meditativa. Poesía y verdad. Poesía y paisaje. Poesía como proceso de experiencia.

Luis Cernuda. Gil y Carrasco. Antonio Machado. Rosalía Castro. Pathetic fallacy. Poetics of Modernity. Sensations. Meditative Poetry. Poetry and Truth. Poetry and Landscape. Poetry as a Process of Experience.

Este trabajo se ha realizado en el seno del Grupo de Investigación HISPANIA (G000208) de la Universidade da Coruña, reconocido como Grupo de Potencial Crecimiento y ha recibido una ayuda de consolidación de la Xunta de Galicia (ref: ED431B 2019/28). 


\title{
Experiencia del poema y asidero plástico, de Luis Cernuda a Rosalía Castro
}

\author{
LUIS CAPARRÓS ESPERANTE \\ Universidade da Coruña
}

En uno de los cuadros de Ocnos, Luis Cernuda recuerda la lección de un antiguo profesor de retórica a quien, por pudor o acaso por soberbia adolescente, llegaría a negar más tarde: 'Él [fue] quien me hizo escribir mis primeros versos, corrigiéndolos luego y dándome como precepto estético el que en mis temas literarios hubiera siempre un asidero plástico.' ${ }^{\prime}$ A este 'asidero' habremos de volver a lo largo de este trabajo, pero antes conviene situarlo en contexto. Aquella temprana lección habría de cobrar toda su relevancia al calor de la experiencia inglesa, cuando conjura definitivamente los vicios de la tradición decimonónica española, mezcla de fanfarria y verbosidad, o de 'garrulería y ampulosidad', en sus propias palabras. ${ }^{2}$ El esprit francés, ahora en clave surrealista, habría dado un primer lavado de cara al persistente gusto tradicional pero los nuevos retos iban más allá de un simple problema de lenguaje.

En 'Historial de un libro', además de recordar una vez más al maestro escolapio, señala otros dos peligros que como poeta habría de conjurar:

Aprendí a evitar, en lo posible, dos vicios literarios que en inglés se conocen, uno, como pathetic fallacy (creo que fue Ruskin quien le llamó así), lo que pudiera traducirse como engaño sentimental, tratando de que el proceso de mi experiencia se objetivara, y no deparase solo al lector su resultado, o sea, una impresión subjetiva; otro, como purple patch o trozo de bravura, la bonitura y lo superfino de la expresión, no condescendiendo con frases que me gustaran por sí mismas y sacrificándolas a la línea del poema, al dibujo de la composición. ${ }^{3}$

El resultado de todo ello apuntaría a una enunciación poética en donde el sujeto procura objetivar (convertir en objeto, distanciar) su 'experiencia emotiva'. O según una primera lectura, que luego habrá que matizar bastante, se trataría de evitar la enunciación directa de la emoción, pues esta impide que se construya en la subjetividad de quien lee.

\footnotetext{
${ }^{1}$ Luis Cernuda, 'Ocnos', en Prosa completa (Barcelona: Barral, 1975), 15-108 (p. 45).

${ }^{2}$ Luis Cernuda, 'Historial de un libro', en Prosa completa, $898-939$ (p. 915).

3 'Historial de un libro', 922-923.
} 
Es, en el fondo, cuestión de matices: 'La luz, los árboles, las flores del paisaje inglés comenzaron a aparecer en mis versos, para matizarlos con un colorido y claroscuro nuevos. Así fue el norte completando en mí, meridional, la gama de emociones sensoriales.' $^{4}$

Es evidente que Cernuda no descubre nada nuevo, pero ni siquiera lo pretende. En estas y otras páginas, Cernuda confronta su marco referencial, en cuanto poeta decididamente moderno, con los lastres arrastrados por una tradición lírica inmediata que no habría acabado de asimilar el lenguaje de esa modernidad, pese a la huella de Darío y a la más sutil de Jiménez o Machado. Es, por ejemplo, la primacía del poema meditativo sobre el puramente musical, o en términos del propio Rubén Darío, en el prólogo a Prosas profanas, admitir que 'la música es solo de la idea, muchas veces' ${ }^{5}$ Cernuda mismo se remite a la 'música callada' de fray Juan de la Cruz. ${ }^{6}$ Acaso fue José Ángel Valente el primero en destacar la conexión de estas ideas de Cernuda con la lectura de Unamuno, a quien se debe entre nosotros la expresión poesía meditativa. Hacia 1899, recuerda Valente, criticaba Unamuno 'la forma poética poco amplia y de cadencias muy tamborilescas en castellano' que lo habrían de conducir 'a pensar el sentimiento y a sentir el pensamiento'. El nuevo tono de Cernuda, prosigue Valente, 'responde al movimiento peculiar del poema meditativo y en ellos la composición de lugar y el análisis mental de sus elementos se combinan de modo típico con el poder unificador del impulso afectivo'? Dicho de otro modo, sensación y pensamiento no serían entidades aparte u hostiles, sino que su complementariedad enriquece el efecto resultante. Sobre sus pasos, Agustín Delgado recordaría otras afirmaciones de Miguel de Unamuno que vienen a reforzar las búsquedas de Cernuda: '...nuestra poesía española es, en cuanto al fondo, pseudopoesía, huera descripción o elocuencia rimada, y en cuanto a la forma, música de bosquimanos, tamborilesca, machacona, en que el compás mata al ritmo.' 8

Por ahí va también la anterior referencia al purple patch, a la bonitura gratuita, a la música vacía de la que Zorrilla sería quizás el mejor ejemplo. Es también la conciencia de que el poema, más allá de las palabras, constituye en sí mismo un trozo de realidad, algo así como un objeto que el lector debe sentir, oler, palpar entre los dedos.

\footnotetext{
4 'Historial de un libro', 923.

${ }^{5}$ Rubén Darío, Poesía (Caracas: Ayacucho, 1985), 180.

6 'Historial de un libro', 927.

7 José Ángel Valente, 'Las palabras de la tribu', en Ensayos, ed. A. Sánchez Robayna y C. Rodríguez Fer (Barcelona: Galaxia Gutenberg / Círculo de Lectores, 2008), 33-265 (pp. 137 y 141).

${ }^{8}$ Cita de Unamuno en Agustín Delgado, La poética de Luis Cernuda (Madrid: Editora Nacional, 1975), 191
} 
El término experiencia va ligado en Cernuda al de proceso: 'el proceso de mi experiencia', y ello es muy atinado, pues se trata de un conocimiento adquirido mediante un proceso mayor o menor de inmersión activa en donde intervienen los sentidos. ${ }^{9} \mathrm{Y}$ para reforzar aún más la idea, en la segunda parte de la cita habla literalmente de 'emociones sensoriales'. ¿Cómo no recordar aquí la frescura de sensación que el gran romántico inglés Coleridge descubría en la lectura de su amigo Wordsworth? Tengamos en cuenta que algo más adelante el propio Cernuda señalará la Biographia Literaria de Coleridge como una de sus cinco fuentes formativas durante el período inglés. ${ }^{10}$ Escribía Coleridge:

Conservar los sentimientos de la infancia en las capacidades de la vida adulta, combinar el sentido de maravilla y novedad del niño ante las escenas que quizá durante cuarenta años nos han sido familiares, 'With sun and moon and stars throughout the year, / And man and woman' [versos de Milton], este es el privilegio y la característica del genio, y uno de los rasgos que lo distinguen del mero talento. Así, el mérito principal del genio y su manifestación más inequívoca es el representar objetos familiares para despertar en la mente de otros un sentimiento semejante al suyo y esa frescura de sensación que es el acompañamiento constante de la convalecencia mental, no menos que de la física. ${ }^{11}$

Esta expresión refuerza la dimensión experiencial del proceso poético. Pues habrá que insistir en que se trata de un proceso, y atención, un proceso compartido necesariamente por quien lee. Según esto, el poema ya escrito vendría a ser la parte central o el eje sobre el que gira la experiencia compartida entre poeta y lector, iniciada antes de la primera palabra escrita y prolongada después por el efecto de la lectura. El poema,

\footnotetext{
${ }^{9}$ Recordemos a este propósito la primera definición del término experiencia en el DLE: 'Hecho de haber sentido, conocido o presenciado alguien algo.' Podría entenderse también como vivencia, según la traducción del Erlebnis alemán introducida en el español por Ortega y Gasset y que refuerza, precisamente, el flanco vivencial de tal fenómeno. Nada tiene esto que ver, en nuestro caso y como resulta obvio, con la llamada Poesía de la experiencia.

10 'Historial de un libro', 923.

${ }^{11}$ Samuel T. Coleridge, Biographia Literaria, ed., trad., prólogo y notas de Gabriel Insausti (Valencia: Pretextos, 2010), 167-168) Las referencias al papel de los sentidos en la percepción poética están presentes a lo largo de las reflexiones de Coleridge o de Wordsworth. Poco antes del texto anterior, publicado originalmente en The Friend, y recogido en la edición de 1817, Coleridge ha apuntado: 'Fue la unión de hondo sentimiento y pensamiento profundo; el hermoso equilibrio entre la veracidad al observar y la facultad de la imaginación al modificar lo observado; y, sobre todo, el original don de difundir un tono, una atmósfera, y con ella la profundidad y la altura del mundo de la idea entre las formas, los incidentes y las situaciones de los que, debido a la visión común, la costumbre había quitado todo el lustre, ocultando el brillo de las nuevas gotas de rocío.' (Biographia, 167). El desgaste de las sensaciones, unido al desgaste de las palabras, es un motivo central en cuanto vamos viendo. Tampoco olvidemos cómo buena parte de estos enfoques estaban ya en la célebre introducción de Wordsworth a las Lyrical Ballads, rasgos que el editor español de la Biographia Literaria, Gabriel Insausti, resume así: 'desprecio de lo meramente ingenioso, abandono de lo que se suele considerar "dicción poética", huida de toda "personificación de ideas abstractas" como recurso para "elevar el estilo" y fidelidad a la naturaleza en las descripciones" (Biographia, 24).
} 
expresado en otros términos, es mucho más que su lectura. El poema acontece, se siente, se vive, se torna experiencia. ${ }^{12}$

De ese mismo hilo se desprende el principal vicio que Cernuda procura esquivar: la verbosidad desatada y sin anclaje en una experiencia sensorial. Esto sucede cuando el lenguaje se mueve en un plano abstracto o cuando la emoción se nombra, pero no se va construyendo en la lectura, con lo cual resulta anulada toda resonancia emocional. A ello se refiere en parte en la segunda cita, cuando menciona la falacia patética, vicio consistente en atribuir cualidades emocionales a objetos o cosas inanimadas y que, de nuevo, sería característico del Romanticismo. Sin embargo, estas notas resultan un tanto apresuradas, pues rebasan con mucho el sentido original de la falacia patética, tal como la había definido John Ruskin. ${ }^{13}$ Para este, viene a ser la confusión inducida por la emoción descontrolada, o el desajuste entre nuestra impresión de lo que son las cosas externas y su auténtica realidad. Ruskin desprecia los términos objetivo o subjetivo que románticos alemanes e ingleses han puesto en circulación, para quedarse solamente con el contraste entre lo que las cosas realmente son y lo que parecen: 'All violent feelings have the same effect. They produce in us a falseness in all our impressions of external things, which I would generally characterize as the "pathetic fallacy". ${ }^{14}$ Las sensaciones violentas o la emoción desmesurada falsean nuestra impresión de las cosas: eso viene a ser la falacia patética. Y algo más adelante, matiza:

Entonces, tenemos los tres rangos: el hombre que percibe correctamente, porque no siente, y para quien la prímula es de manera muy precisa la prímula, pues él no la ama. Luego, en segundo lugar, el hombre que percibe mal, porque siente, y para quien la prímula es algo más que una prímula: una estrella, un sol, un escudo de hada o una doncella abandonada. Y luego, por último, está el hombre que percibe correctamente pese a sus sentimientos, y para quien la prímula es definitivamente solo ella misma: una pequeña flor, aprehendida en el muy simple y frondoso hecho de serlo, sean cuales sean o cuantas se quieran las asociaciones y pasiones amontonadas alrededor. Y, en general, estas tres clases pueden clasificarse, en orden comparativo, como la de quienes no son poetas en absoluto, la de los poetas de segundo orden y la de los poetas del primero. ${ }^{15}$

\footnotetext{
12 «Poesía es algo que se nos hace a nosotros, no solamente que se nos dice. El significado de sus palabras está fuertemente vinculado a la experiencia de ellas.» (Terry Eagleton, Cómo leer un poema (Madrid: Akal, 2010), 31.

${ }^{13}$ De hecho, Cernuda aparece dubitativo ante la exactitud de su referencia: 'creo que fue Ruskin quien le llamó así'.

${ }^{14}$ John Ruskin, 'Of the Pathetic Fallacy', en The Genius of John Ruskin. Selections from His Writings, ed. John D. Rosenberg (Charlottesville y Londres: University of Virginia Press, 1998), 65.

15 'Of the Pathetic Fallacy', 67-68. Me permito traducir el párrafo para la mejor comprensión de sus matices en español.
} 
La atribución de cualidades emocionales a objetos o cosas inanimadas, con su correlato de falsedad, produce ese desplazamiento a que tan aficionados serán los románticos, como llamar cruel a la espuma del mar. ${ }^{16}$ Para Ruskin -digámoslo una vez más- debe existir una clara separación entre la cosa misma, descrita cual ella es, y la emoción que ella desprenda, esto es, aquello que parece. Hay algo en esto de rigor intelectual: el poeta más grande, nos dirá, es aquel que posee una sensibilidad aguda y al mismo tiempo es capaz de controlarla. En última instancia, como señala Ruskin, el engaño consiste en pretender describir de modo directo la emoción sin pasar antes por la descripción del objeto de donde aquella emana, al menos metafóricamente. Luis Cernuda lo explica de modo parecido en otro momento de su 'Historial', a propósito de su clases para el alumnado inglés, en donde tenía bien claro que sus explicaciones debían llevarlos

a ver por sí mismos aquello de que iba a hablarles; que mi tarea consistía en encaminarles y situarles ante la realidad de una obra literaria española. De ahí solo había un paso a comprender que también el trabajo poético creador exigía algo equivalente, no tratando de dar solo al lector el efecto de mi experiencia, sino conduciéndole por el mismo camino que yo había recorrido, por los mismos estados que había experimentado y, al fin, dejarle solo frente al resultado. ${ }^{17}$

Con todo, conviene ir con cautela en este punto. Si la idea expresada por Ruskin a propósito de la poesía de Pope o de los románticos ingleses es de muy discutible aplicación para sus equivalentes españoles, la explicación de Cernuda es más que ajustada. Pienso en concreto en algunos poemas celebrados de Enrique Gil, como 'La gota de rocío' o 'La violeta', y escojo este poeta porque suele ser referencia española para la poesía de paisaje. Ruskin, que censura ese supuesto vicio de atribuir emociones a lo inanimado incluso en un poeta de la altura de Coleridge, aspira a superar una etapa que en el caso español apenas habría llegado a configurarse. Tomemos, por ejemplo, este pasaje de Pope, que Ruskin recoge y después critica a la luz de los razonamientos anteriores:

Dondequiera que camines, vendavales fríos agitarán el claro; Los árboles donde te sientas se apiñarán en una sola sombra; Tu alabanza los pájaros cantarán en cada arboleda, Y al soplo de los vientos alcanzarán los poderes superiores.

\footnotetext{
16 'We are pleased, for instance, with those lines of Kingsley's above quoted, not because they fallaciously describe foam, but because they faithfully describe sorrow' ('Of the Pathetic Fallacy', 68).

17 'Historial de un libro', 921.
} 
Pero si tú cantases, si rivalizases con la tensión de Orfeo,

Los asombrosos bosques volverían a danzar bien pronto;

Las montañas en movimiento escuchan el poderoso reclamo,

¡Y cuelgan arroyos cabeza abajo, escuchando en su caída! ${ }^{18}$

En el fragmento citado, la antropomorfización del paisaje es absoluta. No queda espacio suficiente para su figuración autónoma, debido a la intromisión del sujeto lírico y de la segunda persona, esa amada que va alterando todo a su paso. Pero si es cierto que bailan los bosques, las aves cantan alabanzas o las montañas simplemente escuchan, también podemos sentir agitarse la naturaleza con vida propia entre vientos fríos y trinos en los árboles, con arroyos cayendo, y todo apenas con epítetos. ${ }^{19}$ Por el contrario, en este fragmento del poeta español Enrique Gil, la descripción fracasa de raíz al ser sustituida por epítetos que determinan y subjetivizan aquello que debiéramos ver sin anteojos o, mejor, que debiéramos simplemente ver:

Porque eras melancólica y perdida, y era perdido y lúgubre mi amor; y en ti miré el emblema de mi vida y mi destino, solitaria flor.

Tú allí crecías olorosa y pura con tus moradas hojas de pesar; pasaba entre la yerba tu frescura de la fuente al confuso murmurar.

[...] Yo busqué la hermandad de la desdicha en tu cáliz de aroma y soledad, y a tu ventura asemejé mi dicha, $\mathrm{y}$ a tu prisión mi antigua libertad. ${ }^{20}$

\footnotetext{
${ }^{18}$ Traducción mía del original inglés de Pope. 'Where'er you walk, cool gales shall fan the glade; / Trees, where you sit, shall crowd into a shade; / Your praise the birds shall chant in every grove, / And winds shall waft it to the powers above. / But would you sing, and rival Orpheus' strain, / The wondering forests soon should dance again; / The moving mountains hear the powerful call, / And headlong streams hang, listening, in their fall!' (John Ruskin, 'Of the Pathetic Fallacy', 71).

19 Pope mismo, como anticipándose a las críticas de Ruskin, habría de parodiar esos excesos de artificiosidad en su propia poesía, excesos que era comunes por entonces y que, llegados a fin de siglo, denunciaría Blake: 'Hasta tal punto llegaba esta cerrazón que había lectores que no se hacían a la idea de que se pudiese escribir poesía usando vocabulario que no tuviera algo de poético de antemano, quien se sorprendiera de ver que palabras no marcadas por esta dicción podían tener una dimensión poética, o quien, consecuentemente, no pudiera aguantar la risa al leer poemas con palabras como "manta" o "cuchillo", por lo poco de poético y lo mucho de trivial que tenían, como le ocurría al mismo Samuel Johnson.' (Ricardo Navarrete Franco, 'Palabra de Blake: subjetividad y creatividad en Songs of Inocence and of Experience', en J. A. Pacheco y C. Vera Saura, eds., Romanticismo europeo. Historia, poética e influencias [Sevilla: Universidad, 1998], 69-86 [p. 72].)

${ }^{20}$ Enrique Gil y Carrasco, Poesía, ed. V. Carrera (s.l.: Paradiso_Gutenberg [Biblioteca Gil y Carrasco], 2014), 204.
} 
Gil describe sin transición la emoción resultante, sin que esta brote o se desprenda naturalmente de la cosa aludida, de la violeta en este caso. En ningún momento vemos la flor real y, mucho menos, el terreno donde nace y crece. Los adjetivos pretenden rellenar cuanto falta de presencia cierta, de experiencia sensorial, a modo de atajo hacia una pretendida emoción que el objeto, por sí mismo, no ha logrado generar: melancólica, perdida, lúgubre, pura... Nunca llegamos a distinguir los minúsculos pétalos malvas de la flor real, allá en los márgenes umbríos del camino, sino (abstractas) 'moradas hojas de pesar'. Por si fuese poco, esta expresión invierte el orden natural de la percepción: no son las hojas moradas las que nos arrastran al pesar, sino que es el pesar, la emoción abstracta, la que se adorna con simbólicas hojas moradas. Del mismo modo, el olor de la flor se anula en el sintagma 'cáliz de aroma y soledad'. Todo lo resume el tercer verso, donde de modo explícito la voz poética confiesa su ceguera ante la flor real, de la que solo llega a distinguir su icono o un frío emblema: 'y en ti miré el emblema de mi vida'. Viene a cuento recordar la viveza de aquellas otras violetas que habrá de recuperar Cernuda, un siglo después, que solo alcanzan su pleno significado de 'belleza oculta' ${ }^{21}$ una vez conformadas, ya singulares en su temblor, ya 'leves, mojadas, melodiosas':

Leves, mojadas, melodiosas,

Su oscura luz morada insinuándose

Tal perla vegetal tras verdes valvas,

Son un grito de marzo, un sortilegio

De alas nacientes por el aire tibio. ${ }^{22}$

El Cernuda maduro bebe del romanticismo alemán e inglés que en España apenas había dejado huella en su momento. ${ }^{23}$ Enrique Gil y Carrasco, por su consideración de poeta volcado en el mundo natural, nos sirve así para descubrir algunas claves de la insuficiencia española para el paisaje romántico. ${ }^{24}$ Del mismo modo que Espronceda aparece siempre incómodo ante la naturaleza, él alcanza su nota más brillante -aunque siempre fragmentaria- en la construcción de espacios inasibles, casi becquerianos, donde

\footnotetext{
${ }^{21}$ Philip Silver, De la mano de Cernuda: invitación a la poesía (Madrid: Fundación Juan March y Cátedra, 1989), 68.

${ }^{22}$ Luis Cernuda, Poesía completa, I (Madrid: Siruela, 1993), 311.

${ }^{23}$ Derek Harris, La poesía de Luis Cernuda (Granada: Universidad de Granada, 1992), 144. Es una idea muy presente en las aproximaciones a Cernuda de Derek Harris o de Philip W. Silver: 'Porque la importancia de Cernuda (y de García Lorca) como poeta no está en un supuesto vanguardismo, sino en la manera en que llegan a su sazón en estos dos poetas valores románticos europeos que apenas habían dado señales de vida antes en la poesía española' (Silver, De la mano de Cernuda, 126).

${ }^{24}$ No considero aquí la faceta de Gil como prosista, en concreto los dibujos paisajísticos de El señor de Bembibre, que casi siempre resultan más vívidos e incluso poéticos que los poemas.
} 
lo material es fronterizo de lo espiritual. Es cierto que tal elección resulta perfectamente romántica, incluso muy romántica, mas lo aleja inevitablemente del paisajismo puro que aquí estamos viendo. 'Una gota de rocío', por ejemplo, expresa de manera delicada la huida de lo terrenal y su preferencia por algún punto inestable entre el suelo y el aire:

Que no naciste tú para este suelo, para trocar en lodo tu beldad; tú, más baja que el espíritu del cielo, más alta que la humana vanidad. Quédate ahí pendiente de tu rama, cual blanco mensajero de oración, que solo el verte la esperanza inflama y alienta al quebrantado corazón. ${ }^{25}$

O lo oímos preguntarse en 'La campana de la oración':

¿Quién sabe si hay un punto en el espacio de entrambos mundos eternal confín, más alto que la cresta del palacio y postrer escalón del serafín? ${ }^{26}$

Gil, de un modo u otro, rechaza sobre el papel aquello mismo que se proponía cantar. En 'Sentimientos perdidos' lo expresa de modo coherente con cuanto llevamos visto:

\footnotetext{
¿No sabes, desgraciado, que en el suelo rotas se ven tus alas, y que solo en las bóvedas del cielo desplegarás tus galas? ${ }^{27}$
}

¿Qué paisaje terrestre, qué flores va a cantar cuando solamente le interesan los espacios aéreos? Es cierto que lo mismo podría ser alegado para el caso de Bécquer, pero con independencia de lo que después se comentará, en este siempre aparecen imágenes plásticas, sensoriales, casi fotográficas a veces, que salvan esa distancia entre lo concreto, material, y lo evanescente o ideal:

Yo en los dorados hilos que los insectos cuelgan

\footnotetext{
${ }^{25}$ Gil y Carrasco, Poesía, 91.

${ }^{26}$ Poesía, 96.

${ }^{27}$ Poesía, 99.
} 
me mezco entre los árboles

en la ardorosa siesta. ${ }^{28}$

Todo lo anterior puede ser constatado fácilmente en los textos. Tomemos, por ejemplo, el motivo del árbol. Morse Peckham, en un ensayo clásico, lo utiliza como metáfora de la visión romántica del mundo: un organismo vivo frente a la máquina que ha dominado la anterior visión ilustrada. Que sea el árbol la figura perfecta no resultará extraño, ya que 'el estudio de la literatura decimonónica revela la continua recurrencia de esa imagen'. ${ }^{29} \mathrm{El}$ árbol no se deja fijar, sea en espacio o en tiempo, y se mueve, crece o se liga en cada una de sus partes a cuanto lo rodea, en una relación o dependencia de contigüidad. Pero fijémonos en que hablamos del árbol como un símbolo abierto, naturalmente polivalente, que puede ser a la vez imagen bien establecida del devenir humano y, al mismo tiempo, llega a negar tal identidad al comienzo de cada primavera. A diferencia del ser humano, el árbol renace una y otra vez, pero la marca de temporalidad que arrastra lo acerca de modo inevitable a la antropomorfización, incluso física: puesto de pie, con los brazos en alto, es símbolo contradictorio del propio ser humano.

Pues bien, en Gil y Carrasco y, por extensión, en todos nuestros románticos plenos, se echa en falta ese salto imaginístico que será clave en el Simbolismo y que actúa ya en otros romanticismos. Parece claro que todo salto exige distancia y vacío entre los dos planos en relación, el real y el imaginario. La finura de los detalles, la materialidad de la cosa cantada, su concreción sensible y tangible, son condiciones básicas para la credibilidad del proceso. La comparecencia tras ello de vívidas correspondencias pluriunívocas será el resultado natural de la lectura. Pero el árbol romántico español se queda una vez más en emblema abstracto, en alegoría lógica, en árbol pintado, plano, en sombras de tinta sobre papel. El ciprés será inevitablemente fúnebre, como lloroso el sauce, la palma solitaria y lánguida, el laurel inmortal y glorioso... 'La caída de las hojas', de tema tan esproncediano, resulta un amplio repertorio de árboles alegóricos: 'son hojas el poder y la grandeza', 'árbol de la humana alteza', 'árbol de libertad', 'árbol es, jah!, la gloria de este mundo', etc. ${ }^{30}$ Puede servir también de ejemplo, entre tantos otros, un apólogo de Selgas, fechado en 1849 y titulado 'El sauce y el ciprés', donde la

\footnotetext{
${ }^{28}$ Gustavo Adolfo Bécquer, 'Rima 62, V', en Rimas de Gustavo Adolfo Bécquer, ed. Luis Caparrós Esperante (Alcalá de Henares: Instituto Cervantes / Centro Virtual Cervantes, 2002). También accesible en línea: http://cvc.cervantes.es/obref/rimas/ (consultada: 10/04/2020)

${ }^{29}$ Morse Peckham, 'Toward a Theory of Romanticism', PMLA, 66:2 (March 1951), 5-23 (p.10).

${ }^{30}$ Gil y Carrasco, Poesía, 230, 231 y 232.
} 
acumulación de tópicos, pleonasmos y epítetos innecesarios desarma cualquier imagen sensible que pudiésemos construir mediante la lectura:

Cuando a las puertas de la noche umbría, dejando el prado y la floresta amena, la tarde, melancólica y serena, su misterioso manto recogía,

un macilento sauce se mecía por dar alivio a su constante pena, $\mathrm{y}$, en voz suave y de suspiros llena, al son del viento murmurar se oía $[\ldots]^{31}$

Los inevitables sauces que besan el río alcanzan hasta Bécquer, en su rima 27 (IX). Destaca en el catálogo la palmera, ya con un matiz orientalizante en Gil. También un poema a la palmera consagraría a la jovencísima Carolina Coronado de 1839: la palma solitaria en el desierto, virginal, mística, palma de la gloria, etc. Por cierto, el poema sería contestado de forma bastante equívoca por Espronceda. Enseguida Carolina Coronado encabezará una corriente popularísima de insípidos poemas a flores y tortolitas, que será tema favorito de la lírica femenina del XIX, y no solo de ella. Tanto que Rosalía Castro, que rompe de manera muy consciente con esa tradición, puede escribir en Follas novas (1880):

Daquelas que cantan as pombas i as frores

todos din que teñen alma de muller; pois eu que n'as canto, Virxe da Paloma, ai! de que a terei? ${ }^{32}$

Aún a riesgo de ser reiterativo, habría que insistir en la constante alegorización de los elementos naturales en Gil: 'lámpara del pesar', 'mar de olvido', 'lánguido arenal de la duda', 'flor del alma', 'huracán de las horas', 'mar de la amargura', 'noches del pesar', 'flores de la existencia', 'tempestad del corazón', 'cierzo de las penas'... y podríamos seguir. ${ }^{33}$ El soliloquio meditativo -o filosófico, como diría Jovellanos- ha dado paso en Gil a una poesía trufada de términos abstractos, inertes. También Zorrilla, que pasa por ser un poeta especialmente plástico, fuerza una y otra vez la analogía explícita, nunca simbólica, entre lo natural y lo humano. Para él, todavía es válida la gastada imagen manriqueña del vita flumen como emblema de la vida. A riesgo de parecer tendencioso,

\footnotetext{
${ }^{31}$ Ramón Andrés, ed., Antología poética del Romanticismo español (Barcelona: Planeta, 1987), 188-189.

32 Rosalía Castro, Follas novas, ed. H. Monteagudo y D. Vilavedra (Vigo: Galaxia, 1993), 117.

${ }^{33}$ Gil y Carrasco, Poesía, 100, 129, 136, 151, 153, 159, 198, 202 y 208.
} 
no puedo dejar de acudir a este ejemplo de Granada (1852), expresivo de una sensibilidad anclada aún en la topografía alegórica medieval:

Es la existencia golfo que se agita circundando islas mil, cuyo oleaje de la nada en las playas se limita.

Naves las almas son en que el pasaje hacemos de este golfo, cuyo centro el punto es de partida en este viaje.

Centro es la cuna: una isla mar adentro en la mitad del golfo colocada, do el alma y cuerpo se salen al encuentro.

Al mar cada alma desde allí lanzada va de una en otra isla escala haciendo, hasta dar en las playas de la nada. ${ }^{34}$

Y así podríamos continuar largo tiempo con Nicomedes-Pastor Díaz, Arolas, Salas y Quiroga, Hartzensbuch...

Después de lo visto entenderemos mejor las preocupaciones de Luis Cernuda. Lo que parece precisar con su referencia a la pathetic fallacy es la necesidad de objetivar la experiencia, y según sus propias palabras, de evitar dar al lector directamente 'su resultado, o sea, una impresión subjetiva'. El poeta, precisamente por serlo, no puede saltarse etapas, pues el poema es algo más que un artificio verbal o una suma de palabras: es o debe ser una experiencia mediante la cual son convocadas presencias vivas. Todo ello más allá o más acá de Ruskin. Si cruzamos esta última afirmación con aquella lección sobre el 'asidero plástico', quedará más a la vista lo que rechaza. No sería tanto la atribución de emociones humanas a elementos naturales, que se da por supuesto en la referencia a Ruskin, cuanto falsos atajos como las 'moradas hojas de pesar' de Gil: el adjetivo emocional colgado como peso muerto del nombre común. Los poemas resultantes no nos (con)mueven por la sencilla razón de que ni siquiera llegamos a ver o palpar la flor real de donde parte el poema. Para Cernuda, en fin, se trata de aproximar su dicción poética a la mencionada 'gama de emociones sensoriales' que reivindica a partir de la poesía inglesa.

Resuena siempre en tales cuestionamientos aquella inquietud hegeliana por 'la cosa misma', que la hermenéutica habría de dilucidar en el texto literario. Por ello, la ecuación de Goethe entre Verdad y Ser, esto es, la verdad como sustento y condición del

\footnotetext{
${ }^{34}$ José Zorrilla, Obras completas, ed. N. Alonso Cortés (Valladolid: Librería Santarén, 1943), I, 1138.
} 
ser, se vuelve inmediatamente conflictiva en cuanto se aplica al poema. La verdad del poema es algo infinitamente más complejo que su capacidad de reproducción. ${ }^{35}$

Si hablamos de modernidad en relación a la herencia romántica española, lo hacemos de un proceso fragmentario y largo en el tiempo, donde a veces se queman etapas y otras se dilatan los descubrimientos hasta penetrar bien adentro en el siglo siguiente. En el caso de la pathetic fallacy, lo alarmante no es su perpetuación a destiempo, como critica Ruskin en el caso inglés, sino lisa y llanamente su inexistencia o práctica irrelevancia como procedimiento retórico entre los románticos y postrománticos de España. Y si hay un asunto poético donde esas carencias se hagan más llamativas es en el tratamiento del paisaje y de los elementos naturales.

Meléndez Valdés y Jovellanos se acercaron más y mejor que muchos poetas románticos españoles a una lírica meditativa, en verso blanco, desnuda, atenta a la experiencia de los sentidos como vehículo de la emoción. Supieron sacar partido de las lecciones de Locke y el sensualismo, aunque sus atisbos no valieron para inaugurar o servir de primer eslabón de una nueva sensibilidad romántica a la altura de los tiempos. ${ }^{36}$ Cien años más tarde, todavía Antonio Machado exploraba esas posibilidades en poemas como 'A orillas del Duero', donde podemos ya aspirar aquel 'fuerte olor -romero, tomillo, salvia, espliego-' que nos hace partícipes de una experiencia semejante a la que procura Cernuda. No voy a detenerme demasiado en este poema ni en otros de Campos de Castilla donde asistimos a una secuencia familiar en el paisajismo literario europeo, con fuertes raíces en el Rousseau de las Rêveries o la Nouvelle Héloïse. Todo comienza con un sujeto lírico perfectamente circunstanciado, en lugar real y reconocible, que inicia

\footnotetext{
35 'En todo caso, no es el carácter de reproducción propio de la imagen o la poesía lo que nos permitirá comprender la afirmación de Goethe: "so wahr, so seiend" - "tanta verdad, tanto ser". El objetivo de esto no es ninguna característica particular del caparazón, de su apariencia, de su figura o su diseño, sino algo que está más allá de lo comprensible y cuya inasibilidad ha tenido precisamente un efecto tan impresionante en Goethe. Así es como el arte también nos impresiona a nosotros, ya sea porque encontremos allí una reproducción de algo o por un rechazo total de la idea de reproducción, como puede suceder en la pintura o escultura abstracta. Se trata de algo más que la relación entre reproducción y original. Las obras de arte tienen un nivel superior de ser y eso aparece cuando una obra de arte nos hace vivir una experiencia que nos lleva a decir: esto resulta, y eso es lo que llamamos la verdad.' (Hans-Georg Gadamer, La Philosophie Herméneutique [París: Presses Universitaires de France, 1996], 199. Traducción mía.)

${ }^{36}$ Vid. David T. Gies, 'Sensibilidad y sensualismo en la poesía dieciochesca', en Ideas en sus paisajes. Homenaje al profesor Russell P. Sebold, coord. por G. Carnero Arbat, I. Javier López, E. Rubio Cremades (Alicante: Universidad, 1999), 215-224. Hay versión en línea: http://www.cervantesvirtual.com/nd/ark:/59851/bmc708c0 (consultada: 10/03/2020). También interesa Russell P. Sebold, 'La filosofía de la Ilustración y el nacimiento del Romanticismo español', en Trayectoria del Romanticismo español (Barcelona: Crítica, 1983) 75-108.
} 
su paseo monte arriba hasta alcanzar un punto elevado en donde, y no de modo casual, la descripción panorámica da paso a un proceso meditativo más o menos largo. El salto que liga entorno físico elevado con una secuencia reflexiva es interrumpido por cualquier circunstancia externa, como la simple caída de la noche. Esto lo fuerza al regreso, esto es, a descender de vuelta a lo real y concreto, si no vulgar.

En el caso del poema machadiano, el texto comienza ya con una precisión cronológica: 'Mediaba el mes de julio.' ${ }^{37}$ Sigue una descripción de la subida, donde tienen su sitio elementos como el sudor, el jadeo o el vulgar bastón, hasta que, ya en lo alto y con el horizonte despejado, la mirada se reviste de elementos metafóricos de carácter guerrero, los asociados a la Castilla histórica, junto a los menudos detalles de la vida cotidiana en la Castilla labriega. Hacia la mitad del poema, el verso 'Castilla miserable, ayer dominadora', que resume ambos planos, abre la reflexión histórica y política, tan crítica, que se cerrará con ese mismo verso repetido casi al final del poema. De nuevo, una precisión temporal abre la secuencia final, la del regreso, pero ahora en presente: 'E1 sol va declinando', y ya todo es descripción de caminos blancos y campos ensombrecidos hasta el final. ${ }^{38}$ La meditación surge así con naturalidad de la misma tierra, del suelo, del esfuerzo tanto físico como histórico por ver a lo lejos que hemos compartido paso a paso con el sujeto del poema.

Paul de Man ha comparado pasajes de Rousseau con otros de Wordsworth y Hölderlin y constata cómo en todos ellos se produce el tránsito desde una naturaleza muy real y material -'earthly and material'- hacia otra que pudiera llamarse 'mental and celestial'. El punto de partida se sitúa siempre en un terreno intermedio entre 'the inaccesible mountain peaks and the humanized world of the plains' ${ }^{39}$ En los textos se ligan así opuestos irreconciliables, mediante un intercambio de posiciones y condiciones. ${ }^{40}$ Aunque no nos hayamos detenido más en el poema de Antonio Machado, por ser suficientemente conocido, su simple mención nos permite constatar cómo las viejas lecciones encuentran su camino más tarde o más temprano. Como hará después

\footnotetext{
37 Antonio Machado, Campos de Castilla, $2^{\mathrm{a}}$ ed., ed. Geoffrey Ribbans (Madrid: Cátedra [Letras Hispánicas], 1991), 101.

${ }^{38}$ Campos de Castilla, 103.

${ }^{39}$ Paul De Man, The Rhetoric of Romanticism (Nueva York: Columbia University Press, 1984), 13.

${ }^{40}$ No muy diferente es el modelo de Abrams: 'Observemos tan solo ahora cómo esa metafísica de la interacción sujeto-objeto es paralela a la lírica ejemplar que Wordsworth, siguiendo el ejemplo de Frost at Midnight de Coleridge, estableció en Tintern Abbey: un individuo se enfrenta a una escena natural y hace que acoja su pregunta, y el intercambio entre su espíritu y la naturaleza constituye el poema entero, que generalmente plantea y resuelve una crisis espiritual.' (Meyer H. Abrams, El Romanticismo: tradición y revolución [Madrid: Visor, 1992], 86.)
} 
Luis Cernuda, estos grandes poetas del XX habrán de recorrer a su modo caminos aparentemente cegados por la tradición anterior, pero indispensables para reencontrarse con la modernidad literaria europea en la que pretenden inscribirse.

Paul de Man, precisamente, y a propósito de unos versos de Hölderlin, recordaba que la función propia del lenguaje poético, por oposición al coloquial, consiste en una huida de lo común, del simple intercambio, para recrear el objeto a nueva luz. La metáfora de Hölderlin 'Worte, wie Blumen' - esto es, 'palabras, como flores'- no sugeriría así una comparación entre las cualidades externas de ambos términos, sino que apuntaría al modo en que ambos polos se generan o, más en concreto, a la tensión de un lenguaje que, como hacen las flores, nace de sí mismo, que se quiere real en sí, que pretende ser literal hasta el extremo de ser la cosa misma, no su sombra. En palabras de De Man:

Unlike words, which originate like something else ('like flowers'), flowers originate like themselves: they are literally what they are, definable without the assistance of metaphor. It would follow then, since the intent of the poetic word is to originate like the flower, that it strives to banish all metaphor, to become entirely literal. ${ }^{41}$

Esto es, nombrar en poesía equivale a una nueva experiencia del objeto: 'Poets know of the act of naming — "nun aber nennt er sein Liebstes"- as implying a return to the source, to the pure motion of experience at its beginning. ${ }^{42}$ La literalidad, la proscripción de la sobrecarga metafórica, contribuye a desnudar de adherencias o adornos la presencia de lo nombrado. Es otra vuelta de tuerca sobre la idea con que comenzaba este trabajo: la necesidad de un asidero plástico objetivado para poder hablar de experiencia poética anclada en lo real.

Encuentro todavía hoy esa preocupación en un poeta contemporáneo, Miguel Casado, quien viene hablando y escribiendo en diversos foros sobre lo que él denomina 'deseo de realidad', expresión de una necesidad que trasciende con mucho el conformismo y estatismo de los llamados realismos o realistas. ${ }^{43}$ La apelación a la realidad no remite en este caso a una cuestión de mímesis o de representación, ni pretende cualquier modo de fidelidad al referente. Tampoco tiene que ver con trampantojos o creacionismos. Es algo mucho más ambicioso: que el texto poético sea en sí mismo, sin dejar de ser poema escrito, un trozo de realidad, sujeto como tal a las leyes generales de

\footnotetext{
${ }^{41}$ The Rhetoric of Romanticism, 4.

${ }^{42}$ The Rhetoric of Romanticism, 3.

${ }^{43}$ Miguel Casado, Deseo de realidad. Tres notas de poética (Oviedo: Universidad, 2006).
} 
la percepción. Para ello, el principal obstáculo es el desgaste del lenguaje mismo, su erosión a causa de un uso puramente instrumental, lo que Yves Bonnefoy, citado por Casado, llamaría 'la mayor desgracia de la existencia caída, el lenguaje cegado por su empleo cotidiano' ${ }^{44}$ La huida de esa limitación debiera conducir a una poesía, o mejor, a una escritura donde el pensamiento encontrase su morada natural. El mismo Casado, apoyándose en Deleuze o en Heidegger, nos recuerda que pensamos 'aquello que la escritura nos hace previamente ver', o con más exactitud, 'quien abre la puerta es la escritura, sujeto agente, imprescindible, del conocimiento', más allá incluso del autor. ${ }^{45}$

No es extraño entonces que Casado, a partir de aquí, enhebre la reivindicación rimbaldiana del desarreglo 'de todos los sentidos' con la poética de Alberto Caeiro, el heterónimo de Pessoa. En Alberto Caeiro encontramos del modo más directo la impugnación de aquello que Ruskin -y Cernuda, a partir de él- había denominado falacia patética.

[...] O essencial é saber ver.

Saber ver sem estar a pensar,

Saber ver quando se vê,

E nem pensar quando se vê

Nem ver quando se pensa. ${ }^{46}$

Y la clave está en unos versos anteriores, citados por Casado, que retoman el aspecto clave que venimos persiguiendo: el papel de las sensaciones en el pensamiento poético. 'E os meus pensamentos são todos sensações', escribe Caeiro. Y añade:

Penso com os olhos e com os ouvidos

E com as mãos e os pés

E com o nariz e a boca. ${ }^{47}$

He dejado al margen en todo lo anterior a Gustavo Adolfo Bécquer y a Rosalía Castro, salvo alguna mención suelta. De Bécquer me he ocupado en otras ocasiones y no es en este suelo terrenal donde su mejor poesía se desenvuelve. Recuerdo, con todo, algunos auténticos poemas en prosa donde alcanza insuperable maestría en la recreación de lo natural y en su fusión con la música, precisamente mediante lo sensorial. Podrá no

\footnotetext{
${ }^{44}$ Deseo de realidad, 22.

${ }^{45}$ Deseo de realidad, 26.

${ }^{46}$ Fernando Pessoa, Poesia de Alberto Caeiro, ed. F. Cabral Martins y R. Zenith (Oporto: Assírio \& Alvim, 2009), 58.)

${ }^{47}$ Poesia de Alberto Caeiro, 42.
} 
haber paisaje, pero desde luego hay sensaciones. Pienso en momentos como el de $E l$ Miserere, que no precisan de comentario:

Las gotas de agua que se filtraban por entre las grietas de los rotos arcos y caían sobre las losas con un rumor acompasado, como el de la péndola de un reloj; los gritos del búho, que graznaba refugiado bajo el nimbo de piedra de una imagen en pie aún en el hueco de un muro; el ruido de los reptiles, que, despiertos de su letargo por la tempestad, sacaban sus disformes cabezas de los agujeros donde duermen o se arrastraban por entre los jaramagos y los zarzales que crecían al pie del altar, entre las junturas de las lápidas sepulcrales que formaban el pavimento de la iglesia, todos esos extraños y misteriosos murmullos del campo, de la soledad y de la noche, llegaban perceptibles al oído del romero, que sentado sobre la mutilada estatua de una tumba, aguardaba ansioso la hora que debiera realizarse el prodigio. ${ }^{48}$

Pero también Bécquer, como en los otros casos que hemos venido analizando, tiene muy claro el valor de las sensaciones para cumplir con su particular 'deseo de realidad'. No hace falta ir más allá de la rima 1 (XI) para encontrarnos la insatisfacción con las palabras rutinarias, incapaces de encerrar la visión, lo desconocido, aquello que escapa de la costumbre y de la norma. Desea entonces 'palabras que fuesen a un tiempo / suspiros y risas, colores y notas'. Será palabra, por tanto, transformada, metamorfoseada en sensaciones reales mediante la sinestesia o la visión analógica. Será palabra también que, desde su materialidad, desde esta corporeidad alcanzada, se puede abrir a un pensamiento sin límites, más allá de cualquier constricción lógica o discursiva. El poema, por fin, 'anuncia en la noche del alma una aurora'.

Rosalía Castro es otra cosa. Rosalía tiene un puñado de poemas, en gallego y en español, que rebasan con creces cualquier otra aproximación en estas lenguas a la poética romántica del paisaje. Esto fue posible porque supo percibir, desembarazada de su entorno poético, la eficacia de las notas que Cernuda habrá de señalar mucho tiempo después y que, aún antes, ensayó Antonio Machado o esbozó Bécquer. ${ }^{49}$ Rosalía era moderna a destiempo, si vale la paradoja, y eso explica muchas cosas de su dificultosa recepción. Si bien ciertas lecturas contemporáneas vienen marcando el acento de tal

\footnotetext{
${ }^{48}$ Gustavo Adolfo Bécquer, Leyendas, ed. Joan Estruch (Barcelona: Crítica, 1994), 180.

${ }^{49}$ Rafael Lapesa describió las conexiones de Antonio Machado con Rosalía Castro y Bécquer en un trabajo ya clásico. Vid. Rafael Lapesa, 'Bécquer, Rosalía y Machado', en De la Edad Media a nuestros días (Madrid: Gredos, 1967) 300-306. Vid. también: 'El paisaje, el viajero, el camino blanco y otros motivos poéticos recurrentes en Rosalía de Castro y en Antonio Machado', en Actas do Congreso Internacional de estudios sobre Rosalía de Castro e o seu tempo (Santiago de Compostela: Consello da Cultura Galega / Universidade de Santiago de Compostela, 1986) II, 113-125.
} 
modernidad sobre la constitución de un sujeto agónico, marcado por la escisión romántica entre el ser y el mundo, me parece a mí muchísimo más relevante para tal consideración la conciencia que ella posee de la autonomía del objeto (designado) en cuanto constituyente indispensable del texto poético. ${ }^{50}$

Voy a detenerme en un par de poemas donde se revela de una manera más aguda esa conciencia. Nos servirán además como ejemplificación de cuanto queda escrito. Podrían ser otros, pero por economía verbal opto por dos especialmente brillantes. El primero, que transcribo completo para una lectura más cómoda del comentario, es este:

DiCEN que no hablan las plantas, ni las fuentes, ni los pájaros, ni el onda con sus rumores, ni con su brillo los astros: lo dicen, pero no es cierto, pues siempre cuando yo paso de mí murmuran y exclaman:

- Ahí va la loca, soñando

5 con la eterna primavera de la vida y de los campos, y ya bien pronto, bien pronto, tendrá los cabellos canos, y ve temblando, aterida, que cubre la escarcha el prado.

- Hay canas en mi cabeza, hay en los prados escarcha; mas yo prosigo soñando, pobre, incurable sonámbula, con la eterna primavera de la vida que se apaga y la perenne frescura de los campos y las almas, aunque los unos se agostan y aunque las otras se abrasan.

Astros y fuentes y flores, no murmuréis de mis sueños; sin ellos, ¿cómo admiraros, ni cómo vivir sin ellos? ${ }^{51}$

Por lo pronto, el comienzo nos recuerda aquellos versos de Baudelaire citados siempre como ilustración de la visión analógica del Simbolismo: 'La Nature est un temple

\footnotetext{
${ }^{50}$ Para lo primero, véase: Javier Gómez Montero, 'Referentes europeos do discurso literario de Rosalía de Castro', en Rosalía de Castro no século XXI. Unha nova ollada (Santiago de Compostela: Consello da Cultura Galega, 2014) 525-558. DOI: 10.17075/rcsxxi.2014.028. También: Arturo Leyte, 'Rosalía: la voz inconsciente de su tiempo. Réplica a la ponencia de Javier Gómez-Montero', en Rosalía de Castro no século XXI. Unha nova ollada (Santiago de Compostela: Consello da Cultura Galega, 2014) 559-570. DOI: 10.17075/rcsxxi.2014.029. Discrepo en parte con la interpretación de Arcadio López Casanova, quien entiende la modernidad de Rosalía como anticipación y por tanto desecha la herencia romántica. Precisamente, la indiscutible modernidad de Rosalía tendría mucho que ver con esa recuperación del mejor romanticismo, al igual que sucede en Bécquer o en Baudelaire: 'Xa que logo, o encadramento epocal de Orillas non se pode facer cara atrás -herdo romántico, romanticismo "depurado" (que si vale en parte para o "intimismo" becquerián), nin cara as liñas poéticas coetáneas. A súa cabal comprensión -aínda por facer en moitos aspectos- debe apuntar, segundo sinalamos, ós signos revolucionarios, poderosamente anovadores que trae, e que só anos despois, xa no tránsito ó século XX, vanse establecer como poética canónica, e mesmo van dar sentido e cohesión á evolución da poesía española moderna.' (Arcadio LópezCasanova, 'En las orillas del Sar na poesía española: apuntamentos para una revisión', Follas Novas. Revista de Estudos Rosalianos, 3 [2018], 74-92 [p. 77]).

${ }^{51}$ Rosalía Castro, En las orillas del Sar, ed. Anxo Angueira (Vigo: Xerais, 2019), 278.
} 
où de vivants piliers / Laissent parfoir sortir de confuses paroles. ${ }^{52}$ En el primer poema del libro ya el 'follaje perenne' dejaba oír 'rumores extraños' ${ }^{53}$ Que la Naturaleza habla a quien sabe escucharla, que es un templo sagrado, lo sabían bien los románticos que a ella acudían para encontrarse consigo mismos. El poeta finisecular, tal como lo definirá Rimbaud, será el voyant, el vidente, algo que retomará entre nosotros Rubén Darío. Y ya lo sabía antes la mujer que nos habla desde el texto anterior. La loca gallega, en cuanto loca $-\mathrm{y}$ acaso por gallega-, oye, escucha y entiende las confusas palabras que otros no alcanzan siquiera a percibir. Y atención, pues se trata de saber escuchar, de aguzar el oído y la sensibilidad para que en el poema resuene la voz propia de las cosas, no el monólogo sordo del poeta retórico. La estructura dialógica de nuestro poema lo pone de relieve.

La vuelta de tuerca es que plantas, fuentes, pájaros, olas y estrellas la ven pasar y no la respetan. Murmuran de ella, con una punta de desdén. No es la sacerdotisa de cualquier exótico rito: es tan solo una mujer desquiciada que, contra toda evidencia, parece creerse a salvo del acoso del tiempo. La correspondencia clásica entre la renovada primavera de los campos y el único y último invierno de la vida humana, entre las canas que ya no verdearán y la blanca escarcha abierta a nuevos brotes, toma aquí un sesgo más dramático, pues es la conciencia del sujeto lírico la que sostiene tal ficción. ${ }^{54}$ Pues se trata de una bella mentira con la que procuramos sentido a la sinrazón de la existencia de las cosas. 'As cousas não têm significação: têm existencia', nos recordará Alberto Caeiro. 'As cousas são o único sentido oculto das cousas. ${ }^{55}$ Mediante la mentira poética damos voz y alma (¿y realidad?) a la absoluta alteridad de cuanto nos rodea. Por tal mentira se nos permite palpitar al unísono, pobres humanos, con los ciclos de la naturaleza siempre renovada. ¿No es ese el corazón mismo de la poesía, y acaso del mundo tal como lo conocemos? Poetas como Rosalía han construido y construyen aún nuestra mirada. Ahí apuntan los dos últimos versos: en medio del frío del invierno, con los campos cubiertos por la escarcha, son las ensoñaciones de la loca y pobre y sonámbula poeta las que dan voz, sentido y belleza a astros fuentes y flores. Si consiguen hablarnos, aunque sea para humillarnos con su desprecio, es gracias al sueño de la loca. Y hablan.

\footnotetext{
${ }^{52}$ Charles Baudelaire, Las flores del mal, ed. bilingüe de A. Verjat y L. Martínez de Merlo (Madrid: Cátedra, 1991), 94.

${ }^{53}$ En las orillas del Sar, 189.

${ }^{54}$ Rosso escribe: 'Así, la manida correspondencia entre las estaciones y las etapas de la vida humana ("soñando / con la eterna primavera de la vida y de los campos", v. 5, "Hay canas en mi cabeza, hay en los prados escarcha", v. 8) adquiere matices inéditos, ya que ostenta el filtro cultural (la elaboración de la fantasía soñadora) en que se funda la analogía entre el yo y el cosmos.' (Maria Rosso, 'Rosalía de Castro y las voces líricas de En las orillas del Sar', Cuadernos Aspi, 1 [2013], 89-104 [p. 100].)

${ }^{55}$ Poesia de Alberto Caeiro, 75.
} 
Vayamos a un segundo poema que acabara por definir ese lugar singular de la poesía de Rosalía Castro:

UN MANSO río, una vereda estrecha, un campo solitario y un pinar, y el viejo puente rústico y sencillo completando tan grata soledad.

¿Qué es soledad? Para llenar el mundo basta a veces un solo pensamiento.

Por eso hoy, hartos de belleza, encuentras el puente, el río y el pinar desiertos.

No son nube ni flor los que enamoran;

10 eres tú, corazón, triste o dichoso, ya del dolor y del placer el árbitro, quien seca el mar y hace habitar el polo. ${ }^{56}$

Podemos reconocer en la estructura del poema, pese a su brevedad, los tres momentos o fases que caracterizan el poema romántico de paisaje, tal como lo señalaba Paul de Man: descripción, meditación, conclusión. El poema alcanza la abstracción aupado -o legitimado- por el uso de lo concreto, o dicho al modo de Cernuda, porque parte de un 'asidero plástico'. La descripción, de hecho, traza mediante pinceladas seguras una estampa fácilmente reconocible, que bien podría corresponder a una acuarela en manos de su hijo Ovidio Murguía. Estamos ante un paisaje pintoresco, tal como se define este adjetivo en el siglo XVIII: una escena digna de ser pintada o que pudiera serlo ya, singular, aunque sin lindezas convencionales (lo bello) o acentos dramáticos (lo sublime). Convendrá tener muy presente que en ningún caso se trata de un paisaje fantástico, por utilizar el término habitual en los pintores de la época romántica. Desde el título del libro y mediante la toponimia dispersa en sus versos sabemos que se trata de la vega del río Sar, alrededor de Iria Flavia y Padrón, en tierras gallegas. Esto da una nota de realidad, no de realismo.

La primera duda ante el poema anterior es si estamos ante una muestra de la pathetic fallacy que condenaba Cernuda a partir de Ruskin. Si recordamos la tercera de las definiciones de Ruskin, la correspondiente al buen poeta, podremos tranquilizarnos: 'And then, lastly, there is the man who perceives rightly in spite of his feelings, and to whom the primrose is for ever nothing else than itself - a little flower', y ello, al margen

\footnotetext{
${ }^{56}$ En las orillas del Sar, 203.
} 
de cuantas 'associations and passions' se arracimen alrededor. ${ }^{57} \mathrm{Si}$ el poema anterior nos llevaba a Baudelaire, acaso para este sirviesen los conocidos versos de Verlaine, a los que sin embargo habríamos de dar la vuelta: 'Il pleure dans mon cœur / comme il pleut sur la ville. ${ }^{58}$ En nuestro poema, el paisaje familiar está perfectamente singularizado desde el momento de su percepción y el consiguiente efecto emocional nace de la exactitud con que nos ha sido dibujado. Aunque el río sea manso, vemos solamente un río deslizarse sin prisas. Incluso el grueso del poema habrá de justificar la aplicación del adjetivo 'solitario' al campo y, por extensión, la apropiada impresión de soledad resultante. Podemos percibir un sendero estrecho que, a través de un campo sin nadie, con pinos al fondo, alcanza un puente viejo, 'rústico y sencillo' -esto es, pintoresco-, sobre el río que va fluyendo lento.

La segunda estrofa introduce el espacio de la meditación mediante una oportuna interrogación, que mediante la anadiplosis rescata la última palabra anterior. Soledad... ¿qué es soledad? La soledad es ante todo una emoción, viene a responder la voz lírica, y como tal emoción, se desprende del pensamiento antes que de las cosas mismas. El pensamiento llena o vacía los campos a su gusto y los tiñe aún de esa aureola de belleza que solo él puede conferir. De modo paradójico, el adjetivo que aplica al final a estos elementos ya vividos -o casi mejor, vivenciados - viene desprovisto de connotaciones anímicas: lo que era solitario o soledad en el momento de la descripción, pasa a ser solo campos desiertos al ser envueltos por la reflexión: 'el puente, el río y el pinar desiertos.' . De algún modo, la mirada reflexiva está buscando desnudar ese paisaje de cuanto ella misma añade, como si procurase su verdad esencial, objetiva, libre de adherencias estéticas o sentimentales, desmetaforizada. 'Hartos de belleza', escribe, y de este modo niega incluso la estampa pintoresca e inevitablemente agradable de los cuatro primeros versos. Entretanto, se ha dado una significativa progresión en la forma de presentarse el paisaje descrito: los artículos indeterminados de la primera estrofa dan paso ahora, llegados al final de la segunda, a artículos determinados. 'Un manso río' es ya 'el río' y 'un pinar' se ha convertido en 'el pinar'. Los deícticos nos hablan de un paisaje deglutido al fin por la mirada de la contempladora, que los desnuda, sí, pero a cambio los hace próximos, inmediatos, reconocibles, singulares.

\footnotetext{
57 'Of the Pathetic Fallacy', 67.

${ }^{58}$ Paul Verlaine, Romances sans paroles, préface de Michel Parfenov (París: Classiques Universels, 2001), 135.
} 
La tercera y última estrofa concluye la reflexión con una constatación anclada en el mejor romanticismo europeo, aunque tan descuidada en el caso hispánico: aquella tesis de Schelling según la cual la Naturaleza vendría a ser el espíritu visible y el espíritu sería la Naturaleza invisible. ${ }^{59} \mathrm{Su}$ complementariedad es absoluta, aunque el elemento determinante en el idealismo alemán sea el espíritu, del que la naturaleza sería al cabo una emanación. A fin de cuentas, si la naturaleza es producida por el espíritu, ella misma es generadora de espíritu, un sujeto activo y múltiple que ha dejado de ser natura naturata para ser definitivamente natura naturans. Ya no es máquina, sino ser vivo dotado de cuerpo y espíritu.

Sin embargo, Rosalía Castro marca distancia con la mirada idealista y no se llama a engaño respecto a la verdad del mundo y de las cosas que lo habitan. Es el corazón ‘quien seca el mar y hace habitar el polo'. No nos enamora la propia nube, no nos enamora tampoco la flor, repite Rosalía. Nos enamora nuestro corazón, nuestra sensibilidad para descubrir la belleza o la ternura en las cosas mismas. El último verso lo remacha de manera bellísima, y de nuevo mediante la paradoja, bien lejos de cualquier falacia patética. De este modo, en el poema se representa de manera perfectamente limpia el conflicto irresoluble entre la atracción de lo real-natural y el momento trascendente de la epifanía del yo, volcado en lo invisible, que desarma lo anterior y niega cualquier reconciliación. Ya en un poema anterior, la poeta nos hacía partícipes de la experiencia física de salir al encuentro del pasado, fijado o marcado en la materialidad de las cosas que nos rodean y constituyen:

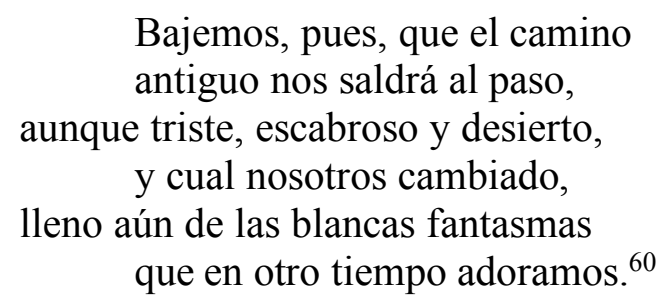

El que nos recibe no es este camino, el de hoy, sino aquel antiguo, reaparecido gracias al presente del texto. También los 'rumores extraños' que veíamos líneas arriba la alcanzaban desde el 'follaje perenne' y, atención al adjetivo, pues tales rumores bien podían llegarle desde otro tiempo lejano, agazapado en estas ramas de ahora, agitadas por el aire. Aún en la misma serie lírica, un poema comienza así:

\footnotetext{
${ }^{59}$ Friedrich Wilhelm Joseph Schelling, Escritos sobre filosofia de la naturaleza, ed. A. Leyte (Madrid: Alianza Editorial, 1996), 110-111.

${ }^{60}$ En las orillas del Sar, 191-192.
} 
Oigo el toque sonoro que entonces a mi lecho a llamarme venía. ${ }^{61}$

Oigo el ayer. Presentes y pasados se entremezclan con naturalidad en el espacio del texto. El poema es ya, de hecho, el lugar de la experiencia. Pero la experiencia será auténtica y su emoción podrá agitarnos solo si cumple la condición de nacer de un paisaje vivido, en donde podamos reconocer nuestras propias marcas, nuestros pasos, con el pinar al fondo y con el viejo puente tantas veces cruzado de camino a casa. Pues no hay validez en aquello que el poema invoca si antes no la tiene el propio texto. Una vez más, la primera responsabilidad del poeta, de la poeta, es con las palabras.

${ }^{61}$ En las orillas del Sar, 191. 